\title{
LETTER
}

\section{Evolution of permeability and fluid pathways in the uppermost oceanic crust inferred from experimental measurements on basalt cores}

\author{
Kenta Kawaguchi and Ikuo Katayama \\ Department of Earth and Planetary Systems Science, Graduate School of Science, Hiroshima University, \\ Higashi-Hiroshima 739-8526, Japan
}

\begin{abstract}
To examine the systematic decrease in permeability with crustal age in the uppermost layer of the oceanic crust, we investigated the effect of mechanical compaction on the permeability of basalt cores from Hole 765D and Hole 456 of the Ocean Drilling Program. The results indicate that permeability systematically decreases with increasing confining pressure. However, the pressure effects observed in the laboratory experiments are insufficient to fully explain the result of in-situ measurements of permeability through the oceanic crust. The permeability of core samples is closely related to porosity, both of which reduce with increasing crustal age. We infer that the evolution of permeability of the oceanic upper crust could be controlled by a reduction in porosity due to carbonate mineral precipitation.
\end{abstract}

Keywords: Oceanic crust, Hydrothermal system, Permeability, Porosity, Carbonate precipitation

\section{INTRODUCTION}

Fluid flow transports heat and solutes within the oceanic crust, thereby modifying its physical state; this has a significant influence on the processes of the oceanic lithosphere as well as on the seismicity at subduction zones (e.g., Fisher, 1998). The lateral fluid flow within the oceanic upper crust is essential to explain seafloor heat flow anomalies and the apparent homogenization of temperature near the boundary between the sediment and basement (e.g., Wolery and Sleep, 1976). In this respect, permeability is an important parameter to consider while studying the circulation of seawater and heat flow within the oceanic upper crust. Fluids tend to circulate in the uppermost basalt layer (2A) far from the ridge, because the permeability of this layer is much higher than that of the overlying pelagic sediments and the underlying massive basalt layer (Fisher, 1998).

In-situ measurements of the permeability of the uppermost basalt layer reveal a systematic decrease with increasing crustal age, where permeability reduces by four orders of magnitude with crustal age $\left(10^{-10} \mathrm{~m}^{2}\right.$ for $0.9 \mathrm{Ma}$

doi:10.2465/jmps.180411

K. Kawaguchi, kenta-kawaguchi@hiroshima-u.ac.jp Corresponding author and $10^{-14} \mathrm{~m}^{2}$ for 7.4 Ma) (Fisher and Becker, 2000; Becker and Davis, 2003). Laboratory measurements of basalt core samples yield a wide range of permeabilities (Karato, 1983; Christensen and Ramananantoandro, 1988); however, the mechanism of the permeability decrease is not well understood. In this study, we measured the permeability of basalt core samples from Ocean Drilling Program sites in the northeastern Indian Ocean (139 Ma) and east of the Mariana Trough $(<1.8 \mathrm{Ma})$. In the laboratory measurements of permeability, we focused on the effect of confining pressure to test whether mechanical compaction is able to explain the age evolution of permeability of the uppermost layer of the oceanic crust.

\section{SAMPLE DESCRIPTIONS AND EXPERIMENTAL METHOD}

All basalt core samples were selected from the oceanic drilling cores stored at the Kochi Core Research Institute, Japan. We performed laboratory measurements of permeability and porosity of basalt samples from Hole 765D located in the northeastern Indian Ocean, and from Hole 456 located in the east of the Mariana Trough. We chose core samples located within the uppermost $200 \mathrm{~m}$ of the basalt layer, with samples from Hole 456 being particu- 

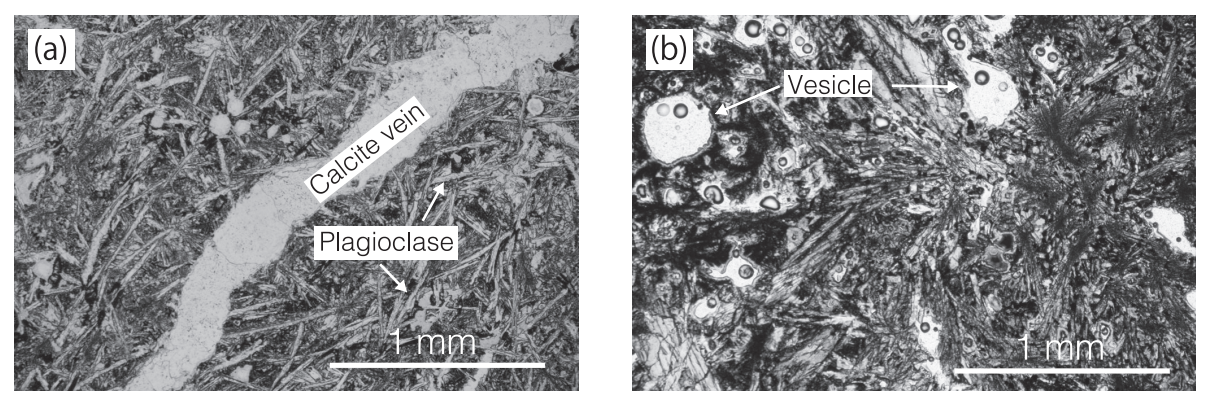

Figure 1. Photomicrographs of studied basalt samples under opened polarizers. The matrix of these samples consists mainly of plagioclase. Basalt samples from Hole 765D (a) contain abundant calcite veins and those from Hole 456 (b) contain several vesicles.

Table 1. Sample description and experimental results

\begin{tabular}{|c|c|c|c|c|c|c|c|}
\hline No. Hole & $\begin{array}{l}\text { Locality } \\
\text { (Age) }\end{array}$ & Rock type & $\begin{array}{l}\text { Depth } \\
(\mathrm{mbsf})\end{array}$ & $\begin{array}{l}\text { Bulk density } \\
\left(\mathrm{g} / \mathrm{cm}^{3}\right)\end{array}$ & $\begin{array}{l}\text { Grain density } \\
\qquad\left(\mathrm{g} / \mathrm{cm}^{3}\right)\end{array}$ & $\begin{array}{l}\text { Porosity } \\
(\%)\end{array}$ & $\begin{array}{l}\text { Permeability } \\
\qquad\left(\mathrm{m}^{2}\right)\end{array}$ \\
\hline 1. $765 \mathrm{D}$ & \multirow{3}{*}{$\begin{array}{l}\text { Indian ocean } \\
\text { (139 Ma) }\end{array}$} & Massive aphyric basalt & $950-960$ & 2.80 & 2.88 & 2.9 & $1.3 \times 10^{-21}$ \\
\hline 2. $765 \mathrm{D}$ & & Massive basalt & $980-990$ & 2.82 & 2.92 & 3.1 & $1.3 \times 10^{-20}$ \\
\hline 3. $765 \mathrm{D}$ & & $\begin{array}{l}\text { Massive sparsely phyric } \\
\text { basalt }\end{array}$ & $1160-1170$ & 2.75 & 2.80 & 2.0 & $1.4 \times 10^{-20}$ \\
\hline 4. 456 & \multirow{3}{*}{$\begin{array}{l}\text { East of Mariana Trough } \\
\qquad(<1.8 \mathrm{Ma})\end{array}$} & Pillow basalt & $133-135$ & 1.98 & 2.75 & 28.1 & $1.1 \times 10^{-16}$ \\
\hline 5. 456 & & Pillow basalt & $133-135$ & 2.18 & 2.89 & 24.6 & $6.9 \times 10^{-17}$ \\
\hline 6. 456 & & Aphyric pillow basalt & $152-153$ & 2.26 & 3.01 & 25.2 & $4.8 \times 10^{-17}$ \\
\hline
\end{tabular}

larly close to the top of the basalt layer. The uppermost oceanic crust is characterized by a uniform structure (Jonathan and Robert, 1994), and therefore these samples likely exhibited a similar pore structure. Samples from Hole 765D are as old as $139 \mathrm{Ma}$, and samples from Hole 456 are young, with ages $<1.8 \mathrm{Ma}$. The samples from Hole $765 \mathrm{D}$ contain calcite veins and have relatively high bulk densities, whereas those from Hole 456 include a small amount of calcite and are characterized by relatively low bulk densities due to the presence of vesicles (Fig. 1). The mean grain densities of Hole $765 \mathrm{D}$ and Hole 456 samples are 2.87 and $2.88 \mathrm{~g} / \mathrm{cm}^{3}$, respectively (Table 1). Thus, although the bulk density of the core samples differs between the two holes, the grain density is similar.

Cylindrical samples approximately $20 \mathrm{~mm}$ in diameter and $10-20 \mathrm{~mm}$ in length were prepared for permeability measurements. The two end-faces of each sample were polished to ensure parallelism. To remove any absorbed water, each specimen was dried at $70{ }^{\circ} \mathrm{C}$ for several days prior to measurement. To measure permeability, we used an inter-vessel deformation and fluid flow apparatus at Hiroshima University, Japan (Katayama et al., 2012). This apparatus is able to measure a wide range of permeability from around $10^{-12}$ to $10^{-22} \mathrm{~m}^{2}$. Samples were covered with a polyolefin sleeve to isolate the pore fluid from the confining pressure fluid. To ensure complete saturation, sample assemblies with the rock core in place were evacuated before pore fluid was injected. Gas permeabilities were measured using a fluid flow method at room temperature under a confining pressure that ranged from 5 to $50 \mathrm{MPa}$.

We used nitrogen gas instead of water as the pore fluid as it has several advantages, such as: (1) experimental times are often shorter; (2) nitrogen gas is chemically inert, so no chemical effects occur; and (3) the viscosity of nitrogen gas is less sensitive to changes in temperature than that of water, and hence the uncertainties in permeability measurements are much smaller than those when water is used as a pore fluid (Tanikawa and Shimamoto, 2009). Gas permeability is up to one order of magnitude higher than water permeability because of the slip flow of gases at pore walls (Klinkenberg effect). Although the absolute value of permeability measured using the gas flow method can differ from that measured using water, we were able to investigate the effect of confining pressure, which is not affected by the type of pore fluid. In comparison to the previous study, we used intrinsic permeability, including the Klinkenberg correction. The porosity was measured with a gas pycnometer, in which the pore volume was calculated from the pressure difference after injecting gas into the sample according to Boyle's law.

\section{EXPERIMENTAL RESULT}

We measured change in permeability during compression under confining pressures $\left(P_{\mathrm{c}}\right)$ of up to $P_{\mathrm{c}}=30 \mathrm{MPa}$ in Hole 765D and up to $P_{\mathrm{c}}=50 \mathrm{MPa}$ in Hole 456 (Fig. 2). Each sample shows three patterns of gas permeability, 

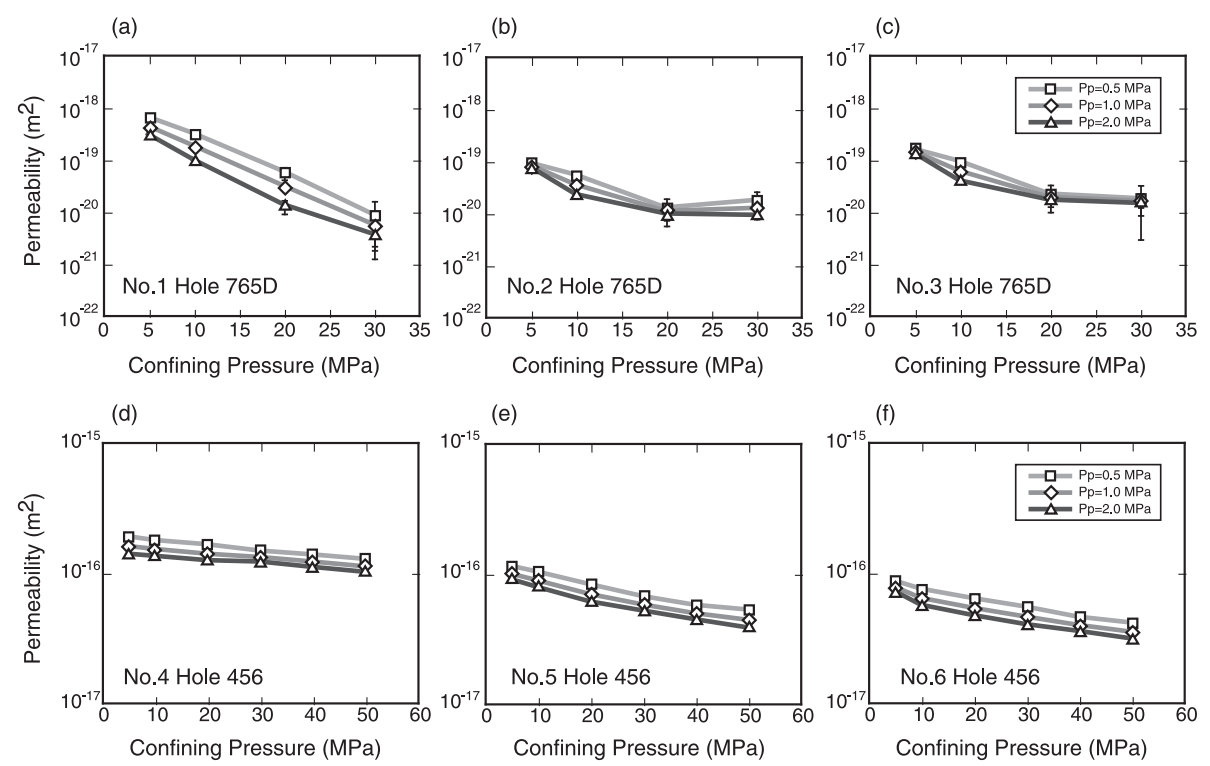

Figure 2. Results of permeability experiments. Each sample shows three patterns of gas permeability, which correspond to three different upstream pore pressures $\left(P_{\mathrm{P}}=\right.$ $0.5,1.0$, and $2.0 \mathrm{MPa})$. In these experiments, fluid flow was driven by the pore pressure gradient, where the downstream pore pressure was set at atmospheric conditions. The errors on the values were estimated from the measurement uncertainty of the fluid flow meter. which correspond to three different pore pressures- $-\left(P_{\mathrm{p}}\right)$ of $P_{\mathrm{p}}=0.5,1.0$, and $2.0 \mathrm{MPa}$. Owing to the Klinkenberg effect, gas permeability is slightly dependent on pore fluid pressure.

In all experiments, gas permeability decreases with increasing confining pressure (Fig. 2). Permeabilities of Hole 765D samples are about three orders of magnitude lower than those of Hole 456 samples. This systematic difference in permeability matches the direction of the porosity differential between the two groups of samples, whereby porosity values are around 3\% for Hole 765D and around $25 \%$ for Hole 456 (Fig. 3). This suggests that the variation in permeability of the samples could be controlled by the variation in porosity and hence, the evolution of permeability of the oceanic crust could be controlled by changes in porosity. It should be noted that porosity measured using the above mentioned method may include isolated pores, whereas only connected pores are responsible for fluid flow. The values of permeability in Figure 3 have been corrected to values of intrinsic permeability with the measured gas permeability at $P_{\mathrm{c}}=10 \mathrm{MPa}$ using the Klinkenberg correction. These data were compared with the experimental data for Hole 504B (Karato, 1983), in which permeabilities were measured at $P_{\mathrm{c}}=$ $15 \mathrm{MPa}$ and upstream pore pressure $=7 \mathrm{MPa}$. Therefore, the effective mean pressure $(\sim 11 \mathrm{MPa})$ was similar to our result. In this experiment, porosity were calculated from the wet-bulk density. The data for Hole 504B plot between those for Hole 456 and Hole 765D (Fig. 3). As the ages of Hole 504B samples are close to $6 \mathrm{Ma}$, and therefore lie between the ages of samples from Holes 456 and 765D, permeability and porosity are systematically correlated to the age of the oceanic crust.

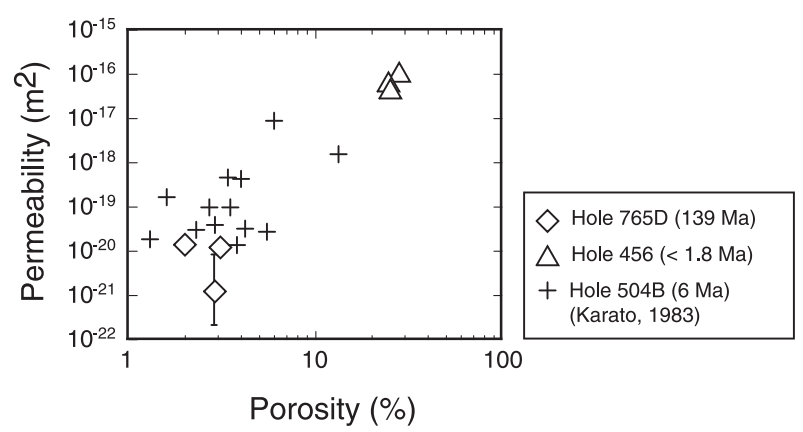

Figure 3. Relationship between permeability and porosity for Holes 765D and 456 (from this study) compared with Hole 504B data (Karato, 1983). The permeability and porosity measurements from Holes 765D and 456 have been corrected to intrinsic permeability values with a measured gas permeability of $P \mathrm{c}=10 \mathrm{MPa}$ using the Klinkenberg correction.

The effect of pressure on permeability differs between samples from Holes 456 and 765D. The results show a weak pressure dependence for Hole 456 and a strong pressure dependence for Hole 765D (Fig. 4). The weak pressure dependence for the young oceanic crust (Hole 456) is consistent with previous laboratory measurements for samples from Hole 504B (Karato, 1983).

\section{DISCUSSIONS}

The laboratory permeabilities measured in this study are considerably lower than the permeabilities of the uppermost few hundred meters of the crustal basement measured using borehole packer methods. This disparity could reflect the difference in dimensions of fluid pathways between the field and laboratory scales. In the uppermost 


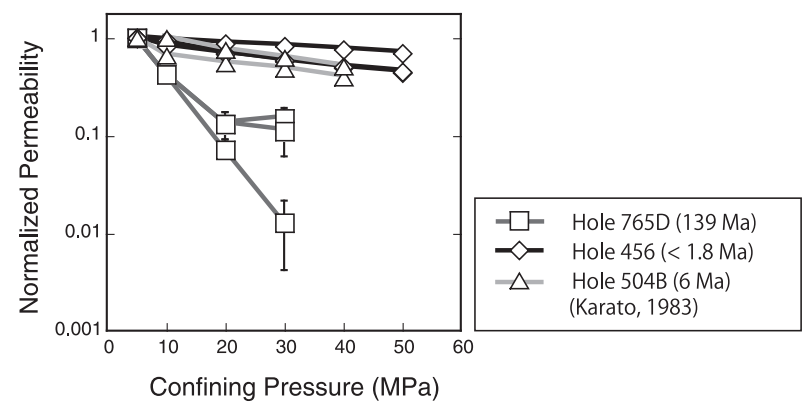

Figure 4. Normalized permeability data. Hole 765D and Hole 456 show data of three samples described in Figure 2. The permeability of old crust (Hole 765D) decreases significantly with increasing confining pressure. In contrast, the permeability of young crust (Holes 456 and 504B) (Karato, 1983) decreases more gradually by less than one order of magnitude.

oceanic crust, large fractures can develop within pillow basalt, including hyaloclastite; fluids tend to flow into these large fracture zones. In contrast, such fractures are not included in hand specimen samples and therefore laboratory measurements do not record their influence. As a consequence, the permeability of the oceanic crust measured from an in situ borehole test is several orders of magnitude higher than that of a laboratory test (Brace, 1984). The absolute values of permeability between experiments and in-situ measurements are systematically different; however, this difference is probably caused by the hydraulic radius of porous media and hence, pressure dependence can be applied to natural systems (e.g., Karato, 1983).

The permeability of the uppermost $200-300 \mathrm{~m}$ of the basalt layer is relatively high but shows a systematic decrease with the oceanic plate age $\left(10^{-10} \mathrm{~m}^{2}\right.$ for $0.9 \mathrm{Ma}$ and $10^{-14} \mathrm{~m}^{2}$ for $7.4 \mathrm{Ma}$ ) (Becker and Davis, 2003). This decrease in permeability is initially caused by mechanical compaction as the confining pressure of the basalt layers increases due to both the increasing thickness of pelagic sediments and the increasing depth of the ocean. Thus, we first estimated the confining pressure of these basalt layers as a function of pelagic sediment thickness and seafloor depth. In this calculation, we incorporated an accumulation rate of pelagic sediment of $5.0 \mathrm{~m} / \mathrm{Myr}$ (Johnson and Pruis, 2003), and used a value for the increase in seafloor depth approximately equal to the square root of crustal age (Parsons and Sclater, 1977); a density of 2.6 $\mathrm{g} / \mathrm{cm}^{3}$ was used for pelagic sediment and $2.7 \mathrm{~g} / \mathrm{cm}^{3}$ for basalt. The results indicated that the confining pressure of the uppermost $300 \mathrm{~m}$ of the basalt layer ranges from 36.0 $\mathrm{MPa}$ for a crustal age of 1.0 Ma to $42.4 \mathrm{MPa}$ for $7.0 \mathrm{Ma}$. Such a small change in confining pressure is insufficient to reduce permeability by four orders of magnitude (Fig. 4), indicating that mechanical compaction alone cannot explain the observed evolution of (i.e., the change in per- meability with crustal age) in the uppermost oceanic crust. According to Figure 4, Hole 765D shows a strong pressure dependence, but Hole 456 shows a weak pressure dependence. This difference in permeability change likely reflects the pore structure. Only connected pores play an important role in permeability (Martin and Michael, 1999). Therefore, the geometry of a pore in each sample could be different.

Based on these experiments, factors other than mechanical compaction are required to explain the decrease in permeability with age in the young oceanic crust within the uppermost $300 \mathrm{~m}$ of the basalt layer. Carbonate veins are ubiquitous in the oceanic crust accreted in ophiolite sections and are precipitated within a few million years of the formation of the crust (Hart and Staudigel, 1978; Richardson et al., 1980; Staudigel et al., 1981). Calcite veins are more abundant in samples from Hole 765D (30 vol\%) than in young samples from Hole 456 (5 vol\%) (Fig. 1). This carbonate precipitation likely results in the reduction of porosity (Fig. 3) and consequently, the permeability also decreases with crustal age. Precipitation might be completed in the first $10 \mathrm{Myr}$ of crustal evolution, since porosities of basalt core samples for Holes 504B and 765D are similar (Fig. 3), suggesting that fluid flow activity might be limited to the relatively young oceanic basements. We suggest that such $\mathrm{CaCO}_{3}$ precipitation might be associated with biotic activity, because Staudigel and Furnes (2004) proposed that more than $50 \%$ of the alternation occurring in the uppermost $300 \mathrm{~m}$ of oceanic basalt is caused by biospheric processes.

\section{ACKNOWLEDGMENTS}

We thank Lallan Gupta and Toshio Hisamitsu for providing core samples, and Keishi Okazaki, Manami Kitamura, Shohei Hamasaki, and Kosuke Kimura for useful discussions and for technical assistance. Samples was supplied by the Ocean Drilling Program. We sincerely thank two anonymous reviewers for improvement the manuscript. This study was supported by the Japan Society for the Promotion of Science (JP15H02147) and a Grant-in-Aid for Science Research on the Innovative Area of Geofluids (JP16H06476).

\section{REFERENCES}

Becker, K. and Davis, E.E. (2003) New evidence for age variation and scale effects of permeabilities of young oceanic crust from borehole thermal and pressure measurements. Earth and Planetary Science Letters, 210, 499-508.

Brace, W.F. (1984) Permeability of crystalline rocks - new in-situ measurements. Journal of Geophysical Research, 89, 43274330 . 
Christensen, N.I. and Ramananantoandro, R. (1988) Permeability of the oceanic crust based on experimental studies of basalt permeability at elevated pressures. Tectonophysics, 149, 181186.

Fisher, A.T. (1998) Permeability within oceanic basaltic crust. Reviews of Geophysics, 36, 143-182.

Fisher, A.T. and Becker, K. (2000) Channelized fluid flow in oceanic crust reconciles heat-flow and permeability data. Nature, 403, 71-76.

Hart, S.R. and Staudigel, H. (1978) Oceanic crust: Age of hydrothermal alternation. Geophysical Research Letters, 5, 10091012.

Johnson, H.P. and Pruis, M.J. (2003) Fluxes of fluid and heat from the oceanic crustal reservoir. Earth and Planetary Science Letters, 216, 565-574.

Jonathan, W.B. and Robert, S.W. (1994) Variation with spreading rate of oceanic crustal thickness and geochemistry. Earth and Planetary Science Letters, 121, 435-449.

Karato, S. (1983) Physical properties of basalts from deep sea drilling project Hole 504B, Costa-Rica Rift. Initial Reports of the Deep Sea Drilling Project, 69, 687-695

Katayama, I., Terada, T., Okazaki, K. and Tanikawa, W. (2012) Episodic tremor and slow slip potentially linked to permeability contrasts at the Moho. Nature Geoscience, 5, 731-734.

Martin, O.S. and Michael, M. (1999) Permeability-porosity relationship in vesicular basalts. Geophysical research letters, 26,
111-114.

Parsons, B. and Sclater, J.G. (1977) An analysis of the variation of ocean floor bathymetry and heat flow with age. Journal of Geophysical Research, 82, 803-827.

Richardson, S.H., Hart, S.R. and Staudigel, H. (1980) Vein mineral ages of old oceanic crust. Journal of Geophysical Research, $85,7195-7200$.

Staudigel, H., Hart, S.R. and Richardson, S.H. (1981) Alternation of the oceanic crust: Processes and timing. Earth and Planetary Science Letters, 52, 311-327.

Staudigel, H. and Furnes, H. (2004) Microbial mediation of oceanic crust alternation. In Hydrology of the Oceanic Lithosphere (Davis, E. and Elderfield, H. Eds.). Cambridge University Press, Cambridge, 608-626.

Tanikawa, W. and Shimamoto, T. (2009) Comparison of Klinkenberg-corrected gas permeability and water permeability in sedimentary rocks. International Journal of Rock Mechanics and Mining Sciences, 46, 1394-1395.

Wolery, T.J. and Sleep, N.H. (1976) Hydrothermal circulation and geochemical flux at mid-ocean ridges. The Journal of Geology, 84, 249-275.

Manuscript received April 11, 2018

Manuscript accepted August 19, 2018

Manuscript handled by Michihiko Nakamura 